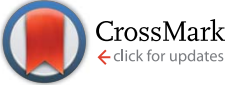

Cite this: Chem. Sci., 2017, 8, 1811

Received 15th October 2016 Accepted 14th November 2016

DOI: $10.1039 / c 6 s c 04609 f$

www.rsc.org/chemicalscience

\title{
Iridium-catalyzed asymmetric hydrogenation of racemic $\alpha$-substituted lactones to chiral diols $\uparrow$
}

\author{
Xiao-Hui Yang, ${ }^{a}$ Hai-Tao Yue, ${ }^{a} \mathrm{Na} \mathrm{Yu},{ }^{a}$ Yi-Pan Li, ${ }^{a}$ Jian-Hua Xie ${ }^{\star a}$ and Qi-Lin Zhou ${ }^{\star a b}$ \\ We report a protocol for the highly efficient iridium-catalyzed asymmetric hydrogenation of racemic \\ $\alpha$-substituted lactones via dynamic kinetic resolution. Using Ir-SpiroPAP $(R)$ - $1 d$ as a catalyst, a wide range \\ of chiral diols were prepared in a high yield (80-95\%) with a high enantioselectivity (up to $95 \%$ ee) under \\ mild reaction conditions. This protocol was used for enantioselective syntheses of (-)-preclamol and \\ a chiral 2,5-disubstituted tetrahydropyran.
}

\section{Introduction}

Transition-metal-catalyzed asymmetric hydrogenation of ketones is an efficient and reliable method for the synthesis of optically active chiral secondary alcohols. ${ }^{1}$ In contrast, the enantioselective synthesis of chiral primary alcohols by catalytic asymmetric hydrogenation of their corresponding aldehydes or esters is difficult, and work on the development of practical methods is underway. In 2007, we reported the first example of the catalytic asymmetric hydrogenation of racemic $\alpha$-branched aldehydes, via dynamic kinetic resolution (DKR), for the synthesis of chiral primary alcohols. ${ }^{2}$ Subsequently, List $^{3}$ and $\mathrm{Lin}^{4}$ et al. also reported the synthesis of chiral primary alcohols, by means of ruthenium-catalyzed asymmetric hydrogenation of racemic $\alpha$-substituted aldehydes. Although a wide range of catalysts have been developed for the hydrogenation of esters, ${ }^{5}$ efficient chiral catalysts for the asymmetric hydrogenation of racemic $\alpha$-substituted esters via DKR are rare. The biggest challenge for the direct asymmetric hydrogenation of racemic esters to form optically active primary alcohols is to find a catalyst that can discriminate between the enantiomers of chiral esters and then hydrogenate them to alcohols selectively. In 2011, Ikariya et al. ${ }^{6}$ described the enantioselective hydrogenation of a racemic mixture of an $\alpha$-substituted $\gamma$-lactone to a chiral 1,4-diol via DKR using chiral ruthenium catalysts bearing chiral 1,2-diamine ligands (Scheme 1). However, the enantioselectivity of the reaction was low (up to $32 \%$ ee). Recently, as part of our work on the asymmetric hydrogenation of ketones, we found that chiral Ru-SDPs/diamine catalysts and chiral Ir-SpiroPAP catalysts can also mediate the hydrogenation of ester groups. ${ }^{7}$

${ }^{a}$ State Key Laboratory and Institute of Elemento-Organic Chemistry, Nankai University, Tianjin 300071, China. E-mail: jhxie@nankai.edu.cn; qlzhou@nankai.edu.cn ${ }^{b}$ Collaborative Innovation Center of Chemical Science and Engineering (Tianjin), Nankai University, Tianjin 300071, China

$\dagger$ Electronic supplementary information (ESI) available. See DOI: $10.1039 / \mathrm{c} 6 \mathrm{sc} 04609 \mathrm{f}$
In this communication, we report a protocol for the Ir-SpiroPAP-catalyzed asymmetric hydrogenation of racemic $\alpha$-substituted lactones to afford chiral diols in a high yield (80-95\%) with a high enantioselectivity (up to $95 \%$ ee, Scheme 1).

\section{Results and discussion}

We initially performed the hydrogenation of racemic $\alpha$-phenyl $\delta$-valerolactone (2a) to evaluate the activity and enantioselectivity of various catalysts (Table 1 ). Under the previously reported reaction conditions ${ }^{7 b}$ (catalyst loading $=0.2 \mathrm{~mol} \%(\mathrm{~S} / \mathrm{C}$ $=500),[2 \mathrm{a}]=0.25 \mathrm{M},\left[{ }^{t} \mathrm{BuOK}\right]=0.04 \mathrm{M}, \mathrm{EtOH}, 10$ atm $\mathrm{H}_{2}$ and $25-30{ }^{\circ} \mathrm{C}$ ), no reaction occurred in the presence of the catalyst

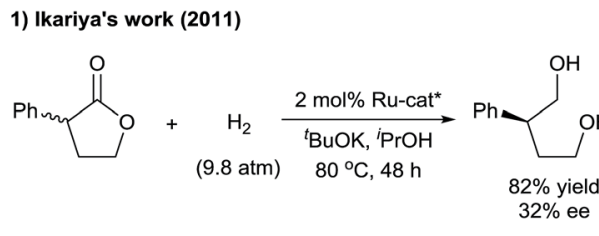

2) This work
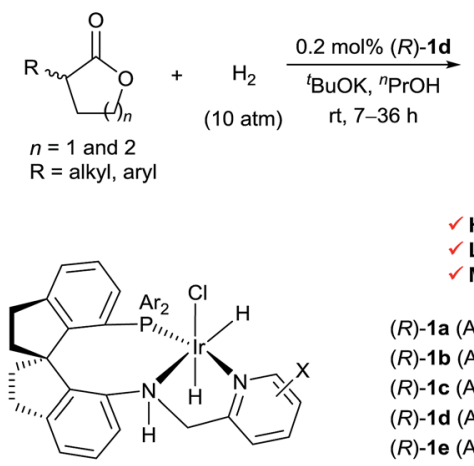

Ir-(R)-SpiroPAP $((R)-1)$

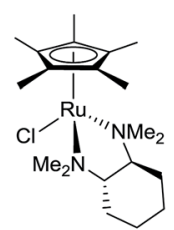

Ru-cat*
Scheme 1 Asymmetric hydrogenation of racemic $\alpha$-substituted lactones via DKR. 
Table 1 Asymmetric hydrogenation of $2 \mathrm{a}$. Optimizing reaction conditions $^{a}$
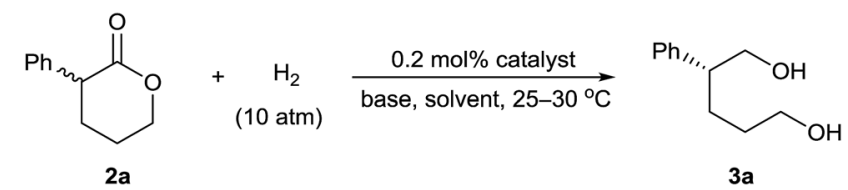

$3 a$

\begin{tabular}{|c|c|c|c|c|c|c|c|}
\hline Entry & Cat. & Base & [Base] & Solvent & Time (h) & Yield $^{b}(\%)$ & $\mathrm{ee}^{c}(\%)$ \\
\hline 1 & $(R)-\mathbf{1 d}$ & ${ }^{t} \mathrm{BuOK}$ & 0.04 & EtOH & 24 & ND & ND \\
\hline 2 & $(R)-\mathbf{1 d}$ & ${ }^{t} \mathrm{BuOK}$ & 0.06 & EtOH & 24 & 15 & 91 \\
\hline 3 & $(R)-\mathbf{1 d}$ & ${ }^{t} \mathrm{BuOK}$ & 0.25 & $\mathrm{EtOH}$ & 10 & 91 & 92 \\
\hline 4 & $(R)-\mathbf{1 a}$ & ${ }^{t} \mathrm{BuOK}$ & 0.25 & EtOH & 10 & 93 & 90 \\
\hline 5 & $(R)-\mathbf{1 b}$ & ${ }^{t} \mathrm{BuOK}$ & 0.25 & EtOH & 10 & 92 & 90 \\
\hline 6 & $(R)-1 c$ & ${ }^{t} \mathrm{BuOK}$ & 0.25 & EtOH & 10 & 92 & 91 \\
\hline 7 & $(R)-\mathbf{1 e}$ & ${ }^{t} \mathrm{BuOK}$ & 0.25 & EtOH & 17 & 91 & 90 \\
\hline 8 & $(R)-\mathbf{1 f}$ & ${ }^{t} \mathrm{BuOK}$ & 0.25 & EtOH & 10 & 92 & 90 \\
\hline 9 & $(R)-\mathbf{1 d}$ & ${ }^{t} \mathrm{BuOK}$ & 0.25 & $\mathrm{MeOH}$ & 7 & 10 & 86 \\
\hline 10 & $(R)-\mathbf{1 d}$ & ${ }^{t} \mathrm{BuOK}$ & 0.25 & ${ }^{n} \mathrm{PrOH}$ & 10 & 92 & 93 \\
\hline 11 & $(R)-\mathbf{1 d}$ & ${ }^{t} \mathrm{BuOK}$ & 0.25 & ${ }^{i} \mathrm{PrOH}$ & 8 & 89 & 74 \\
\hline 12 & $(R)-\mathbf{1 d}$ & ${ }^{t} \mathrm{BuONa}$ & 0.25 & ${ }^{n} \mathrm{PrOH}$ & 10 & 91 & 93 \\
\hline 13 & $(R)-\mathbf{1 d}$ & $\mathrm{KOH}$ & 0.25 & ${ }^{n} \mathrm{PrOH}$ & 20 & 48 & 93 \\
\hline 14 & $(R)-\mathbf{1 d}$ & $\mathrm{NaOH}$ & 0.25 & ${ }^{n} \mathrm{PrOH}$ & 20 & 36 & 93 \\
\hline 15 & $(R)-\mathbf{1 d}$ & $\mathrm{K}_{2} \mathrm{CO}_{3}$ & 0.25 & ${ }^{n} \mathrm{PrOH}$ & 20 & 21 & 92 \\
\hline
\end{tabular}

${ }^{a}$ Reaction conditions: $1.0 \mathrm{mmol}$ scale, [2a] $=0.25 \mathrm{M}, 0.2 \mathrm{~mol} \%$ of catalyst, solvent $(4.0 \mathrm{~mL})$ and room temperature $\left(25-30{ }^{\circ} \mathrm{C}\right) .{ }^{b}$ Isolated yield. ${ }^{c}$ Determined by HPLC using a chiral column. The absolute configuration of $\mathbf{3 a}$ is $R$ determined by comparing its optical rotation with the literature data (see ESI).

$(R)$-1d (entry 1). However, when the concentration of ${ }^{t} \mathrm{BuOK}$ was increased to $0.06 \mathrm{M}$, the hydrogenation reaction occurred and provided $(R)-3 \mathbf{a}$ in $15 \%$ yield with $91 \%$ ee (entry 2 ); further increasing the concentration of ${ }^{t} \mathrm{BuOK}$ increased the reaction rate and the yield of $3 \mathrm{a}$ substantially. For example, when $0.25 \mathrm{M}$ ${ }^{t} \mathrm{BuOK}\left(2 \mathrm{a} /{ }^{t} \mathrm{BuOK} /(R)-\mathbf{1 d}=500: 500: 1\right)$ was used, the reaction was complete within $10 \mathrm{~h}$, providing $(R)-3 \mathrm{a}$ in $91 \%$ yield with $92 \%$ ee (entry 3). The absolute configuration of $(R)-3 a$ was determined by comparing the sign of its optical rotation with the literature data. ${ }^{8}$ Evaluation of various chiral Ir-SpiroPAP catalysts $(R)-\mathbf{1}$ revealed that the substituents on the pyridine and phenyl groups of the catalysts had little effect on the yield or enantioselectivity (entries 4-8), with (R)-1d giving the best results. Experiments with various solvents showed that ${ }^{n} \mathrm{PrOH}$ was suitable (entries 9-11); the reaction was complete within $10 \mathrm{~h}$, affording $(R)-3 \mathrm{a}$ in $92 \%$ yield with $93 \%$ ee. In addition to ${ }^{t} \mathrm{BuOK},{ }^{t} \mathrm{BuONa}$ also gave a high yield with a high enantioselectivity, but the use of $\mathrm{KOH}, \mathrm{NaOH}$, or $\mathrm{K}_{2} \mathrm{CO}_{3}$ resulted in low yields (entries 12-15).

To evaluate the substrate scope of the reaction, we investigated a wide range of racemic $\alpha$-substituted $\delta$-valerolactones under the established reaction conditions (Table 2). For racemic $\alpha$-aryl-substituted $\delta$-valerolactones 2a-i (entries 1-9), neither electron-donating nor electron-withdrawing groups on the phenyl ring of the substrates had much effect on the enantioselectivity of the reaction, but substrates with an electron-
Table 2 Asymmetric hydrogenation of racemic $\alpha$-substituted lactones to chiral diols with $(R)-1 \mathrm{~d}^{a}$

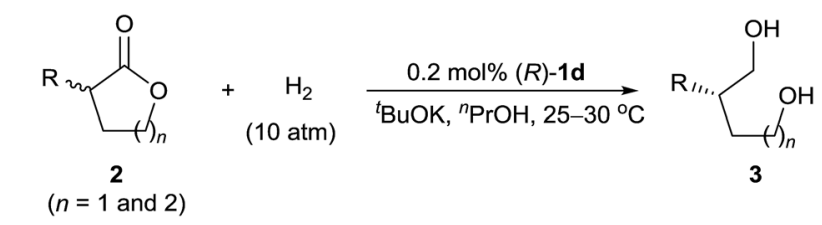

\begin{tabular}{|c|c|c|c|c|c|c|}
\hline Entry & $\mathrm{R}$ & $n$ & 3 & Time (h) & Yield $^{b}(\%)$ & $\operatorname{ee}^{c}(\%)$ \\
\hline $1^{d}$ & $\mathrm{C}_{6} \mathrm{H}_{5}$ & 2 & $3 a$ & 10 & 92 & $93(R)$ \\
\hline 2 & $4-\mathrm{ClC}_{6} \mathrm{H}_{4}$ & 2 & $3 \mathbf{b}$ & 7 & 93 & 93 \\
\hline 3 & $4-\mathrm{MeC}_{6} \mathrm{H}_{4}$ & 2 & $3 \mathbf{c}$ & 9 & 92 & 93 \\
\hline 4 & $4-\mathrm{MeOC}_{6} \mathrm{H}_{4}$ & 2 & $3 d$ & 10 & 93 & 93 \\
\hline 5 & $3-\mathrm{ClC}_{6} \mathrm{H}_{4}$ & 2 & $3 \mathbf{e}$ & 7 & 95 & 92 \\
\hline 6 & $3-\mathrm{MeC}_{6} \mathrm{H}_{4}$ & 2 & $3 f$ & 10 & 91 & 93 \\
\hline 7 & $3-\mathrm{MeOC}_{6} \mathrm{H}_{4}$ & 2 & $3 g$ & 10 & 93 & $92(R)$ \\
\hline $8^{d}$ & $3,4-\mathrm{Cl}_{2} \mathrm{C}_{6} \mathrm{H}_{3}$ & 2 & $3 \mathbf{h}$ & 7 & 94 & 92 \\
\hline 9 & $3,4-(\mathrm{MeO})_{2} \mathrm{C}_{6} \mathrm{H}_{3}$ & 2 & $3 \mathbf{i}$ & 10 & 91 & 91 \\
\hline 10 & $2-\mathrm{ClC}_{6} \mathrm{H}_{4}$ & 2 & $3 \mathbf{j}$ & 13 & 89 & 78 \\
\hline 11 & 2- $\mathrm{MeC}_{6} \mathrm{H}_{4}$ & 2 & $3 \mathbf{k}$ & 36 & 84 & 77 \\
\hline 12 & $2-\mathrm{MeOC}_{6} \mathrm{H}_{4}$ & 2 & 31 & 20 & 88 & 86 \\
\hline $13^{d}$ & $\mathrm{Me}$ & 2 & $3 m$ & 8 & 92 & $91(S)$ \\
\hline 14 & Et & 2 & $3 n$ & 12 & 90 & 87 \\
\hline $15^{d}$ & ${ }^{i} \mathrm{Pr}$ & 2 & 30 & 12 & 90 & $95(R)$ \\
\hline $16^{d}$ & $\mathrm{CH}_{2}=\mathrm{CHCH}_{2} \mathrm{CH}_{2}$ & 2 & $3 p$ & 12 & 91 & $88(S)$ \\
\hline 17 & $\mathrm{C}_{6} \mathrm{H}_{5}$ & 1 & $3 q$ & 10 & 80 & $80(R)$ \\
\hline 18 & $\mathrm{Me}$ & 1 & $3 \mathbf{r}$ & 10 & 82 & $69(S)$ \\
\hline
\end{tabular}

${ }^{a}$ Reaction conditions: $1.0 \mathrm{mmol}$ scale, [substrate $]=0.25 \mathrm{M},\left[{ }^{t} \mathrm{BuOK}\right]=$ $0.25 \mathrm{M}, 0.2 \mathrm{~mol} \%$ of $(R)-1 \mathrm{~d},{ }^{n} \mathrm{PrOH}(4.0 \mathrm{~mL})$ and room temperature (25$\left.30{ }^{\circ} \mathrm{C}\right) .{ }^{b}$ Isolated yield. ${ }^{c}$ Determined by HPLC using a chiral column. ${ }^{d}$ The absolute configuration of the product is determined by comparing its optical rotation with the literature data (see ESI).

withdrawing group (entries 2, 5, and 8) showed a higher reaction rate than those with an electron-donating group.

In addition, owing to steric effects, substrates with an ortho-substituent on the phenyl ring gave lower reaction rates, yields, and enantioselectivities (entries 10-12). The hydrogenation of $\alpha$-alkyl-substituted $\delta$-valerolactones $2 \mathbf{m}-\mathbf{p}$ also worked well, affording the corresponding 1,5-diols $3 \mathbf{m}-\mathbf{p}$ in high yields and high enantioselectivities (entries 13-16). Catalyst $(R)-1 d$ also catalyzed the hydrogenation of racemic $\alpha$-substituted $\gamma$-butyrolactones $2 \mathbf{q}$ and $2 \mathbf{2 r}$, providing the 1,4 -diols $\mathbf{3 q}$ (80\% ee) and $3 \mathbf{r}$ (69\% ee), respectively (entries 17 and 18).

We investigated the pathway of the hydrogenation of racemic $\alpha$-substituted lactones 2 by ${ }^{1} \mathrm{H}$ NMR. As shown in Fig. 1, after reaction for $0.5 \mathrm{~h}$ under the optimal reaction conditions, rac-2a was converted to the hydroxyl ester 4, propyl 5-hydroxy-2-phenylpentanoate, in $62 \%$ yield with no ee and the diol $3 \mathrm{a}$ in $38 \%$ yield with $93 \%$ ee. Over the following $10 \mathrm{~h}$, the amount of the hydroxyl ester 4 gradually decreased, and the amount of the diol 3a increased. Only a trace amount of lactone 2a was detected from 2 min after the reaction started.

Direct hydrogenation of the hydroxyl ester 4 with catalyst $(R)$-1d provided the diol 3a in 93\% yield with 93\% ee, which is the same as the result obtained from the hydrogenation of lactone 2a (Scheme 2). We also conducted the hydrogenation of 


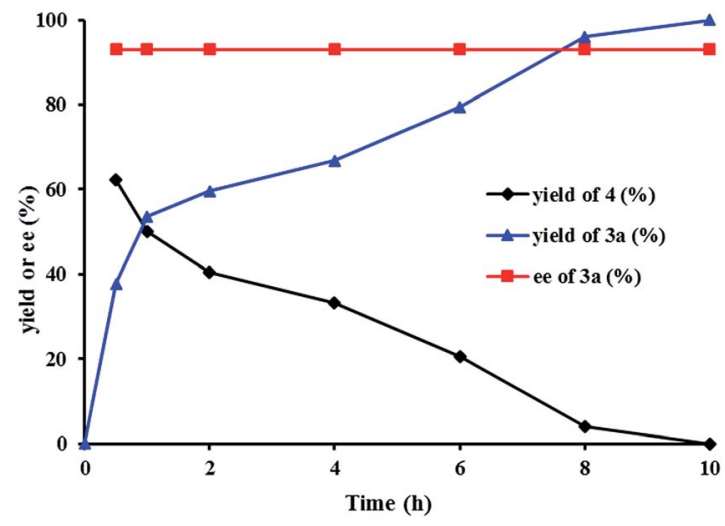

Fig. 1 The plots of the hydrogenation of rac-2a with $(R)-1 d$.
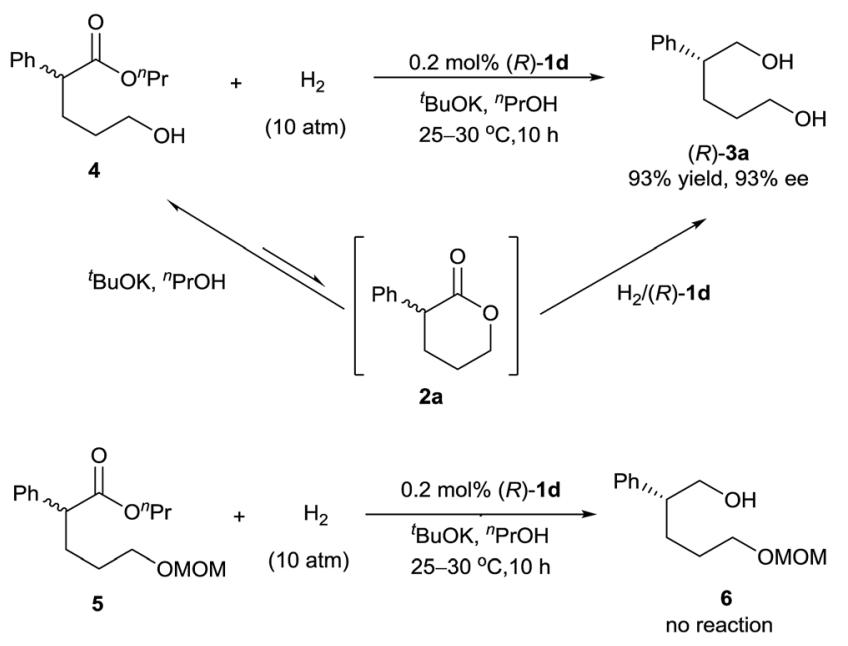

Scheme 2 Asymmetric hydrogenation of esters 4 and 5 with $(R)-1 \mathrm{~d}$

the ester $\mathbf{5}$, which has a $\delta-\mathrm{OCH}_{2} \mathrm{OMe}$ group instead of a $\delta-\mathrm{OH}$ group as in the hydroxyl ester 4 , and observed no reaction. These results indicated that the hydroxyl group of ester $\mathbf{4}$ was crucial for the hydrogenation. Thus, although the lactone $2 \mathrm{a}$ was readily alcoholized to the hydroxyl ester $\mathbf{4}$ under the reaction conditions, the hydrogenation of 2a occurred inevitably via its lactone form (Scheme 2). ${ }^{7 b, c}$<smiles>COc1cccc([C@H]2CCCOC2=O)c1</smiles>

rac-2g $1.65 \mathrm{~g}(80 \mathrm{mmol})$

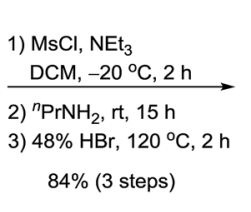

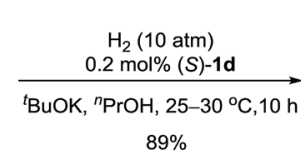
$89 \%$

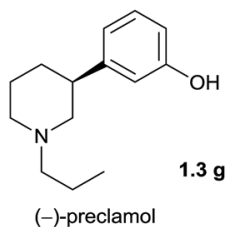

Scheme 3 Enantioselective synthesis of (-)-preclamol.

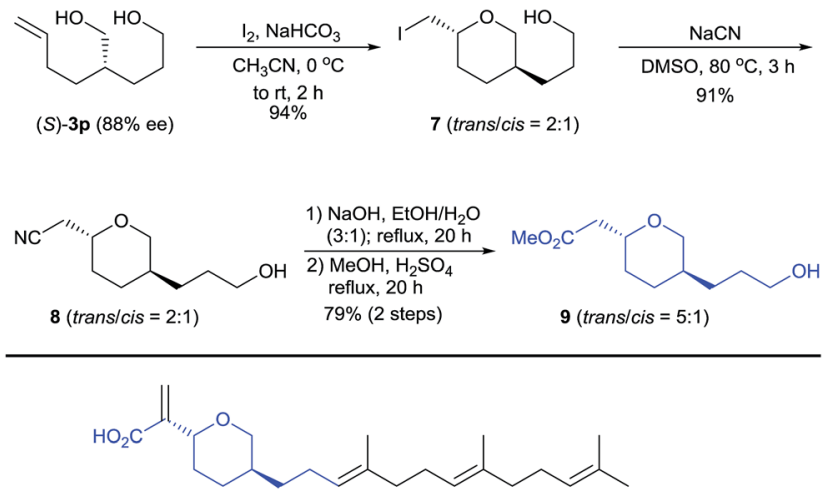

(+)-rhopaloic acid A

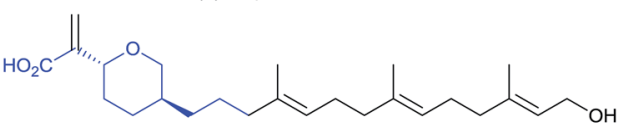

(+)-barangcadoic acid $\mathrm{A}$

Scheme 4 Enantioselective synthesis of a chiral 2,5-disubstituted tetrahydropyran.

Chiral 3-aryl/alkyl substituted piperidines are part of an important class of bioactive heterocyclic compounds, ${ }^{9}$ but they are difficult to synthesize in their optically active forms. ${ }^{10} \mathrm{By}$ using the catalyst $(S)$-1d, we synthesized (-)-preclamol, ${ }^{11}$ which is a candidate drug for the treatment of neurological disorders such as Parkinson's disease. ${ }^{12}$ The hydrogenation of rac-2g $(1.65 \mathrm{~g})$ catalyzed by $(S)-\mathbf{1 d}$ afforded the diol $(S)-3 \mathbf{g}(89 \%$ yield and $93 \%$ ee), which was subsequently transformed to (-)-preclamol by activation with methanesulfonyl chloride, substitution/cyclization with $n$-propylamine, and demethylation with hydrobromic acid $(84 \%$ yield over three steps, Scheme 3).

Diol $(S)-3 \mathbf{p}$ is a useful building block for the synthesis of chiral 2,5-disubstituted tetrahydropyrans, which occur in many biologically active natural products such as the terpenoids rhopaloic acid $\mathrm{A}^{13}$ and barangcadoic acid $\mathrm{A}^{14}$ (Scheme 4), isolated from marine sponges. Iodoetherification of $(S)-3 \mathbf{p}$ with iodine ${ }^{15}$ produced the tetrahydropyran 7 in $94 \%$ yield as a $2: 1$ trans/cis mixture. Nucleophilic substitution of tetrahydropyran 7 with $\mathrm{NaCN}$ afforded the nitrile 8 (trans/cis $=2: 1$ ). Hydrolysis of the nitrile 8 and its subsequent esterification with $\mathrm{MeOH}$ afforded the tetrahydropyran 9 in a $72 \%$ yield with a higher trans/cis ratio $(5: 1)$. Thus, this protocol represents a potential method for the construction of the chiral core structures of rhopaloic acid A and barangcadoic acid A. ${ }^{16}$

\section{Conclusions}

In conclusion, we have developed a protocol for the highly efficient iridium-catalyzed asymmetric hydrogenation of racemic $\alpha$-substituted lactones via DKR. Using an Ir-SpiroPAP catalyst, a series of racemic $\alpha$-substituted lactones were hydrogenated to chiral diols in high yield with high enantioselectivity under mild reaction conditions. The protocol was used for the enantioselective syntheses of (-)-preclamol and a chiral 2,5-disubstituted tetrahydropyran. 


\section{Experimental}

\section{General procedure for the asymmetric hydrogenation of 2}

Into a $20 \mathrm{~mL}$ hydrogenation vessel in an autoclave was added racemic $\alpha$-substituted $\delta$-valerolactone $2(1.0 \mathrm{mmol})$, a solution of iridium catalyst $(R)-\mathbf{1 d}$ in ${ }^{n} \mathrm{PrOH}$ (dried with MS $4 \AA$ for $12 \mathrm{~h}$, $0.002 \mathrm{mmol} \mathrm{mL}{ }^{-1}, 1.0 \mathrm{~mL}, 0.002 \mathrm{mmol}$ ), a solution of ${ }^{t} \mathrm{BuOK}$ in ${ }^{n} \mathrm{PrOH}\left(0.5 \mathrm{mmol} \mathrm{mL}{ }^{-1}, 2.0 \mathrm{~mL}, 1.0 \mathrm{mmol}\right)$ and ${ }^{n} \mathrm{PrOH}(1.0 \mathrm{~mL})$. The autoclave was purged with hydrogen by pressurizing to $5 \mathrm{~atm}$ and releasing the pressure. This procedure was repeated three times and then the autoclave was pressurized to $10 \mathrm{~atm}$ of $\mathrm{H}_{2}$. The reaction mixture was stirred at room temperature (25-30 ${ }^{\circ} \mathrm{C}$ ) until no obvious hydrogen pressure drop was observed. The reaction mixture was then quenched with saturated $\mathrm{NH}_{4} \mathrm{Cl}(5 \mathrm{~mL})$ and extracted with EtOAc $(5 \mathrm{~mL} \times 3)$. The combined extracts were washed with brine, dried over anhydrous $\mathrm{MgSO}_{4}$ and concentrated in vacuo. The residue was purified by flash column chromatography on a silica gel using petroleum ether/ethyl acetate as the eluent to afford the chiral diols 3 . The ee values of the chiral diols 3 were determined by HPLC using a chiral column.

\section{Acknowledgements}

This project was supported by the National Natural Science Foundation of China, the National Basic Research Program of China (973 Program) (No. 2012CB821600) and the "111" project (No. B06005) of the Ministry of Education of China.

\section{Notes and references}

1 (a) The Handbook of Homogeneous Hydrogenation, ed. J. G. de Vries and C. J. Elsevier, Wiley-VCH, Weinheim, 2007; (b) B. Zhao, Z. Han and K. Ding, Angew. Chem., Int. Ed., 2013, 52, 4744; (c) J.-H. Xie and Q.-L. Zhou, Acta Chimica Sinica, 2014, 72, 778 .

2 (a) J.-H. Xie, Z.-T. Zhou, W.-L. Kong and Q.-L. Zhou, J. Am. Chem. Soc., 2007, 129, 1868. For reviews on dynamic kinetic resolution, see: (b) T. Ohkuma and R. Noyori, in The Handbook of Homogeneous Hydrogenation, ed. J. G. de Vries and C. J. Elsevier, Wiley-VCH, Weinheim, 2007, p. 1105; (c) H. Pellissier, Tetrahedron, 2011, 67, 3769.

3 X. Li and B. List, Chem. Commun., 2007, 1739.

4 D. J. Mihalcik and W. Lin, Angew. Chem., Int. Ed., 2008, 47, 6229.

5 For reviews on catalytic hydrogenation of esters, see: (a) M. L. Clarke and G. J. Roff, in The Handbook of Homogeneous Hydrogenation, ed. J. G. de Vries and C. J. Elsevier, Wiley, New York, 2007, p. 413; (b) M. Ito and T. Ikariya, Chem. Commun., 2007, 5134; (c) P. A. Dub and T. Ikariya, ACS Catal., 2012, 2, 1718; for selected recent papers, see: (d) J. Zhang, G. Leitus, Y. Ben-David and D. Milstein, Angew. Chem., Int. Ed., 2006, 45, 1113; (e) L. A. Saudan, C. M. Saudan, C. Debieux and P. Wyss,
Angew. Chem., Int. Ed., 2007, 46, 7473; (f) D. Spasyuk, S. Smith and D. G. Gusev, Angew. Chem., Int. Ed., 2012, 51, 2772; $(g)$ D. Spasyuk, S. Smith and D. G. Gusev, Angew. Chem., Int. Ed., 2013, 52, 2538.

6 M. Ito, T. Ootsuka, R. Watari, A. Shiibashi, A. Himizu and T. Ikariya, J. Am. Chem. Soc., 2011, 133, 4240.

7 (a) C. Liu, J.-H. Xie, Y.-L. Li, J.-Q. Chen and Q.-L. Zhou, Angew. Chem., Int. Ed., 2013, 52, 593; (b) X.-H. Yang, J.-H. Xie, W.-P. Liu and Q.-L. Zhou, Angew. Chem., Int. Ed., 2013, 52, 7833; (c) X.-H. Yang, K. Wang, S.-F. Zhu, J.-H. Xie and Q.-L. Zhou, J. Am. Chem. Soc., 2014, 136, 17426.

8 S. S. M. A. Hakim and T. Sugimura, Org. Lett., 2010, 12, 3626. 9 (a) M. J. Schneider, Alkaloids: Chem. Biol. Perspect., 1996, 10, 155; (b) R. J. Andersen, R. W. M. Van Soest and F. Kong, Alkaloids: Chem. Biol. Perspect., 1996, 10, 301; (c) L. Cervetto, G. C. Demontis, G. Giannaccini, B. Longoni, B. Macchia, M. Macchia, A. Martinelli and E. Orlandini, J. Med. Chem., 1998, 41, 4933; (d) M. Macchia, L. Cervetto, G. C. Demontis, B. Longoni, F. Minutolo, E. Orlandini, G. Ortore, C. Papi, A. Sbrana and B. Macchia, J. Med. Chem., 2003, 46, 161.

10 F. Colpaert, S. Mangelinckx and N. De Kimpe, J. Org. Chem., 2011, 76, 234 andreferences therein.

11 For selected papers on asymmetric synthesis of preclamol, see: (a) J. Hu, Y. Lu, Y. Li and J. Zhou, Chem. Commun., 2013, 49, 9425; (b) Z. Huang, Z. Chen, L. H. Lim, G. C. P. Quang, H. Hirao and J. Zhou, Angew. Chem., Int. Ed., 2013, 52, 5807; (c) J. Y. Hamilton, D. Sarlah and E. M. Carreira, Angew. Chem., Int. Ed., 2015, 54, 7644; (d) T. Jia, P. Cao, B. Wang, Y. Lou, X. Yin, M. Wang and J. Liao, J. Am. Chem. Soc., 2015, 137, 13760.

12 (a) U. Hacksell, L. E. Arvidsson, U. Svensson, J. L. G. Nilsson, D. Sanchez, H. Wikstroem, P. Lindberg, S. Hjorth and A. Carlsson, J. Med. Chem., 1981, 24, 1475; (b) C. Sonesson, C.-H. Lin, L. Hansson, N. Waters, K. Svensson, A. Carlsson, M. W. Smith and H. Wikstroem, J. Med. Chem., 1994, 37, 2735.

13 (a) S. Ohta, M. Uno, M. Yoshimura, Y. Hiraga and S. Ikegami, Tetrahedron Lett., 1996, 37, 2265; (b) M. Yanai, S. Ohta, E. Ohta and S. Ikegami, Tetrahedron, 1998, 54, 15607.

14 K. S. Craig, D. E. Williams, I. Hollander, E. Frommer, R. Mallon, K. Collins, D. Wojciechowicz, A. Tahir, R. Van Soest and R. J. Andersen, Tetrahedron Lett., 2002, 43, 4801. 15 L. F. Tietze and C. Schneider, J. Org. Chem., 1991, 56, 2476. 16 For selected papers on the synthesis of rhopaloic acid A and its analogues, see: (a) K. Kadota and K. Ogasawara, Heterocycles, 2003, 59, 485; (b) J. C. R. Brioche, K. M. Goodenough, D. J. Whatrup and J. P. A. Harrity, Org. Lett., 2007, 9, 3941; (c) J. C. R. Brioche, K. M. Goodenough, D. J. Whatrup and J. P. A. Harrity, J. Org. Chem., 2008, 73, 1946; (d) Y. Shi and A. H. Hoveyda, Angew. Chem., Int. Ed., 2016, 55, 3455. 